\title{
THE ROLE OF SELENIUM MICRONUTRIENTS AS ANTIOXIDANTS IN EXPOSURE TO E-CIGARETTE SMOKE
}

\author{
RIVAN VIRLANDO SURYADINATA ${ }^{1,2}$, MERRYANA ADRIANI ${ }^{3}$, SANTI MARTINI $^{4}$, SRI SUMARMI ${ }^{3}$, \\ BAMBANG WIRJATMADI ${ }^{3 *}$
}

${ }^{1}$ Doctoral Program of Public Health, Faculty of Public Health, Universitas Airlangga, Surabaya, Indonesia. ${ }^{2}$ Department of Public Health, Faculty of Medicine, Universitas Surabaya (UBAYA), Surabaya, Indonesia. ${ }^{3}$ Department of Nutrition, Faculty of Public Health, Universitas Airlangga, Surabaya, Indonesia. ${ }^{4}$ Department of Epidemiology, Faculty of Public Health, Universitas Airlangga, Surabaya, Indonesia

Email: b.wirjatmadi@fkm.unair.ac.id

Received: 09 July 2019, Revised and Accepted: 15 July 2019

ABSTRACT

Objective: E-cigarette products have resulted in various controversies concerning their posed impacts on health. Some argue that exposure to e-cigarette smoke could improve free radicals in the body; thus, it causes harming impacts on health. Peroral selenium (Se) administration can increase superoxide dismutase (SOD) and glutathione peroxidase (GPx) serving as antioxidants in the body.

Methods: This research is an experimental study aiming to analyze the effectiveness of Se to decrease free radical due to exposure to e-cigarette smoke as one of the preventive actions. The research was carried out to male Wistar rats with exposure to e-cigarette smoke and peroral Se intake with different time and duration of administration.

Results: Research results showed a decrease of antioxidant SOD and GPx in the administration of exposure to e-cigarette smoke, and they gradually increased after Se administration $(\mathrm{p}=0.000)$. Meanwhile, the malondialdehyde level was inversely proportional compared to antioxidant SOD and GPx.

Conclusion: Se is a micronutrient that can reduce free radicals due to exposure to e-cigarette smoke through enhancement of antioxidant enzymes such as SOD and GPX.

Keywords: Selenium, Malondialdehyde, E-cigarette, Glutathione peroxidase, Superoxide dismutase.

(C) 2019 The Authors. Published by Innovare Academic Sciences Pvt Ltd. This is an open access article under the CC BY license (http://creativecommons. org/licenses/by/4. 0/) DOI: http://dx.doi.org/10.22159/ajpcr.2019.v12i8.34454

\section{INTRODUCTION}

The use of electronic cigarettes keeps on increasing annually. It is caused by the absence of specific regulations targeting the use of e-cigarettes leading to their use at any place [1]. Besides, their great shapes and models compared to tobacco cigarettes along with their massive promotion attract young people [2]. Electronic cigarettes are also claimed as tools to reduce or stop the use of tobacco cigarettes. They are also considered to be safer and have less risk because they only produce water vapor claimed not to endanger health [3]. Various studies have shown the dangerous risks posed by exposure to electronic cigarettes. The danger of electronic cigarettes has been estimated to be greater compared to the one in tobacco cigarettes. Even in passive smokers inhaling the smoke of e-cigarettes, nicotine is also found in blood [4]. The inhaled smoke of e-cigarettes entering airways can trigger the existence of free radicals. The amount enhancement of excessive free radicals will cause amount imbalance of free radicals and antioxidants in the body so that oxidative stress occurs [5].

Free radicals in the body are molecules having one or more electrons which are not in pairs, but very reactive, and unstable. Free radicals can react fast with other molecules by catching electrons to stabilize themselves. Free radicals will be balanced by taking electrons, whereas the molecules under attacked will change into other free radicals causing damage to cells [6]. Oxidative stress will enhance lipid peroxidase on the attacked cell membrane [7]. One of lipid peroxidase results due to free radicals is malondialdehyde (MDA), which can be used as a parameter of free radicals enhancement in the body [8].

Reduction of free radicals can be done by administering antioxidants. Antioxidants mechanism works by giving electrons to the free radicals; thereby, they can stop cell damage process [9]. Besides, antioxidants will neutralize free radicals so that they will not have any ability to take electrons from the cells [10]. Physiologically, human body can neutralize free radicals when their amount is not excessive [11]. This is done by means of endogenous antioxidant defense mechanism $[12,13]$. However, when there is a lack of endogenous antioxidants, the body needs exogenous antioxidants [14]. Various ways to enhance antioxidants in the body include adding intake of exogenous antioxidants from food, supplements, and doing sports [15]. Some of the endogenous antioxidants needed to neutralize free radicals free are glutathione peroxidase (GPx) and superoxide dismutase (SOD). Antioxidant GPx is an intracellular antioxidant enzyme which enzymatically changes hydrogen peroxidase $\left(\mathrm{H}_{2} \mathrm{O}_{2}\right)$ to water $\left(\mathrm{H}_{2} \mathrm{O}\right)$ [16]. Meanwhile, antioxidant SOD plays a role in changing superoxide radical into $\mathrm{H}_{2} \mathrm{O}_{2}$ [17].

Selenium (Se) has antioxidant and immunomodulation functions. In the body, Se is used to synthesize amino acid, called selenocysteine, which is very important for selenoprotein formation. Selenoprotein is composed of 25 types in human body and classified based on its function as various enzymes which one of them is antioxidant GPx [18]. Thus, Se is often called as an enzymatic component of GPx [19]. The main form of Se is selenomethionine, commonly found in food [20]. Main sources of Se in food are selenomethionine amino acid (in the form of cereals) and selenocysteine (from animal products). Some plants such as beet leaves, cabbage, and garlic contain a high level of Se, reaching up to $50 \%$ in the form of selenate. Se can also be obtained from supplements in the forms of selenate, selenite, selenomethionine, or other forms of Se [21]. Moreover, Se has a quite significant function for human's health because it is able to join into protein to be selenocysteine. Se effects have been proven, ranging from antioxidant to anti-inflammatory effects [22]. 
Various studies have proven that SE suppresses reactive oxygen species formation by improving GPx activity [23]. Antioxidant SOD is more influenced by copper and zinc micronutrients. Hence, the role of Se against SOD enhancement still needs further research [24].

\section{METHODS}

This research is an experimental study using a post-test control group design (Ethical Approval No:103/EA/KEPK/2018). The research was conducted for 5 weeks utilizing male Wistar rats (Rattus norvegicus). The research was divided into six groups with different treatments in each group.

The first group was the negative control group where the experimental animals did not undergo any intervention for 4 weeks. The second group was the cigarette control group where the experimental animals were given intervention of exposure to e-cigarette smoke for 4 weeks. The third group was the Se control group where the experimental animals were given intervention of peroral Se intake for 4 weeks. The fourth group was treatment Group I where the experimental animals were given exposure to e-cigarette smoke on the $1^{\text {st }}$ week. Next, on the second until the $5^{\text {th }}$ week, they were given exposure to e-cigarette smoke and peroral Se. The fifth group was treatment Group II, where the experimental animals were given exposure to e-cigarette smoke and peroral Se for 4 weeks. The sixth group was treatment Group III where the experimental animals were given peroral Se in the $1^{\text {st }}$ week, next during the second until the $5^{\text {th }}$ week they were given exposure to e-cigarette smoke and peroral Se.

\section{Mice}

Male Wistar rats aged 2-3 months weighing 150-200 g were used as animal models. The Wistar rats were never been subjects research and did not have macroscopic abnormalities. The experimental animals are adapted first for 5 days before giving intervention. The research was conducted in the Laboratory of the Faculty of Medicine, Universitas Airlangga.

Se

Se per oral used is an active form of selenomethionine. The recommended dose for adults is $200 \mathrm{mcg} /$ day. Using the conversion table Laurence and Bacharach, calculation obtained was $3.6 \mathrm{mcg}$. Thus, the dosage that can be given to male white rats of the Wistar strain is $3.6 \mathrm{mcg} /$ day per each experimental animal.

\section{E-cigarette}

The solution of an e-cigarette used contains $6 \mathrm{mg}$ of nicotine. The room where exposure to e-cigarette smoke measures $50 \mathrm{~cm} \times 40 \mathrm{~cm} \times 20 \mathrm{~cm}$ there is space a pipe will be passed which can expend e-cigarette smoke. The exposure to e-cigarette smoke exposure is adjusted for the length of time planned for the research.

\section{Measurement of GPx level in the blood}

GPx level in blood measured using an enzyme-linked immunosorbent assay (ELISA) Kit, which can be applied in the quantitative in vitro determination of Rat GPx1 concentration in serum, plasma, and other biological fluids. The ELISA kit uses the competitive-ELISA method. The kit had been coated with Rat GPx1 as a specific antibody. The rat GPx1 concentration in the sample was then determined by comparing the sample result to the standard curve.

\section{Measurement of SOD level in blood}

SOD level in blood measured using an ELISA kit which can be applied in the quantitative in vitro determination of rat SOD1 concentration in serum, plasma, and other biological fluids. The ELISA kit uses the competitive-ELISA method. The kit had been coated with rat SOD1 as a specific antibody. The rat SOD 1 concentration in the sample was then determined by comparing the sample OD to the standard curve. reactive substance (TBARS) assay. Measurements were carried out using the bioassay system based on the reaction of TBARS with TBA in forming pink-colored compounds. The color intensity was measured at $535 \mathrm{~nm}$ or with fluorescence intensity at $560 \mathrm{~nm} / 585 \mathrm{~nm}$ which was directly proportional to the concentration of TBARS in the sample.

\section{Statistika}

The collected data will be statistically tested using SPSS version 20 to analyze the difference and influence of Se on SOD levels, GPx, and MDA in the blood in all groups.

\section{RESULTS}

SOD levels in blood as a result of exposure to e-cigarette smoke Research results were obtained by comparing the levels of SOD in each group. Based on Fig. 1, the average value and difference of levels of SOD in each group can be known. The results showed that the cigarette control group had the lowest average value reaching $2.29 \pm 0.12$. Meanwhile, in the Se control group, it had the highest average value reaching $5.05 \pm 0.16$. In the treatment groups, there was an increase in the average value of SOD sequentially.

To fulfill the parametric test requirements, the research results were subjected to a normality test ( $p>0.05)$ and homogeneity test ( $p=0.008)$. Based on Table 1, Kruskal-Wallis test was conducted to know the difference of SOD levels in the groups $(\mathrm{p}=0.000)$.

GPx levels in blood as a result of exposure to e-cigarette smoke Research results were obtained by comparing levels of GPx in each group. Based on Fig. 2, the average value and difference of levels of GPx in each group can be known. The results showed that the cigarette control group had the lowest average value reaching 85.6 \pm 8.96 . Meanwhile, in the Se control group, it had the highest average value reaching $330.6 \pm 13.22$. In the treatment groups, there was an increase in the average value of GPx sequentially.

To fulfill the parametric test requirements, the research results were subjected to normality test $(\mathrm{p}>0.05)$ and homogeneity test $(\mathrm{p}=0.385)$. Based on Table 2, analysis of variance test was conducted to know the difference of GPx levels in the groups $(\mathrm{p}=0.000)$.

Table 1: Kruskal-Wallis test for superoxide dismutase in each group

\begin{tabular}{llll}
\hline Groups & Definition & Mean \pm SD & p-value \\
\hline I & Negative control group & $4.64 \pm 0.27$ & 0.000 \\
II & Cigarette control group & $2.29 \pm 0.12$ & \\
III & Selenium control group & $5.05 \pm 0.16$ & \\
IV & Treatment Group I & $3.00 \pm 0.04$ & \\
V & Treatment Group II & $3.33 \pm 0.1$ & \\
VI & Treatment Group III & $4.67 \pm 0.07$ & \\
\hline
\end{tabular}

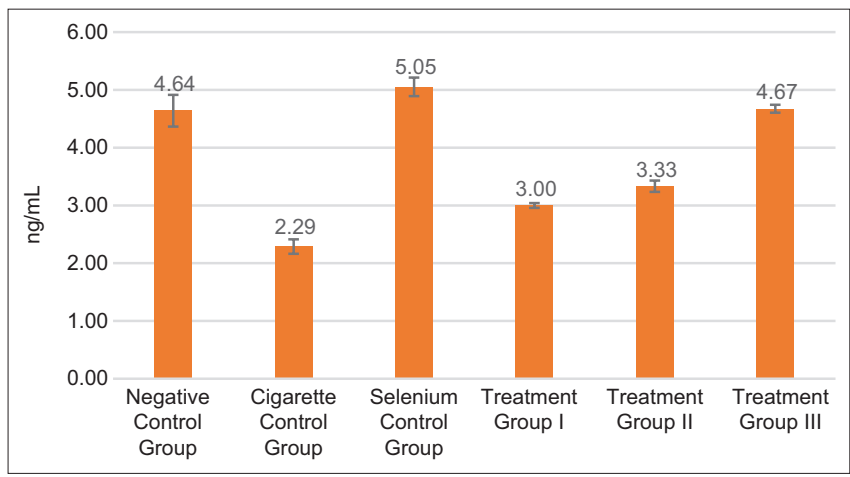

Fig. 1: The mean value for superoxide dismutase in each group 


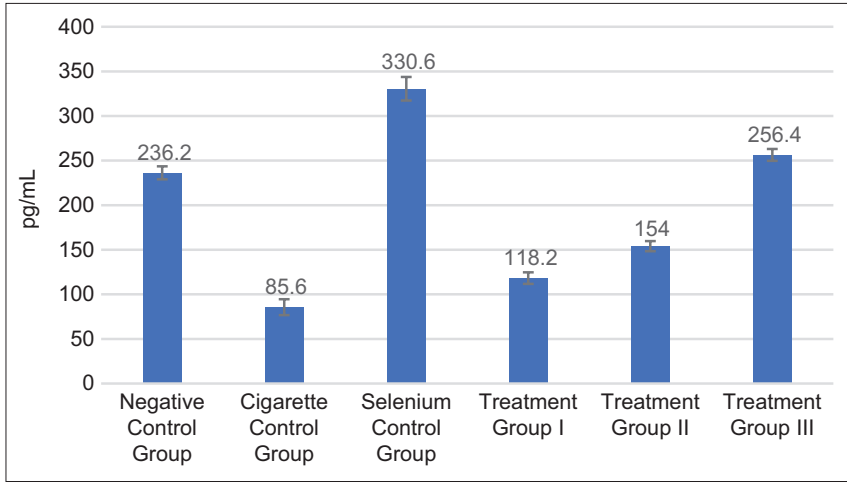

Fig. 2: The mean value for glutathione peroxidase in each group

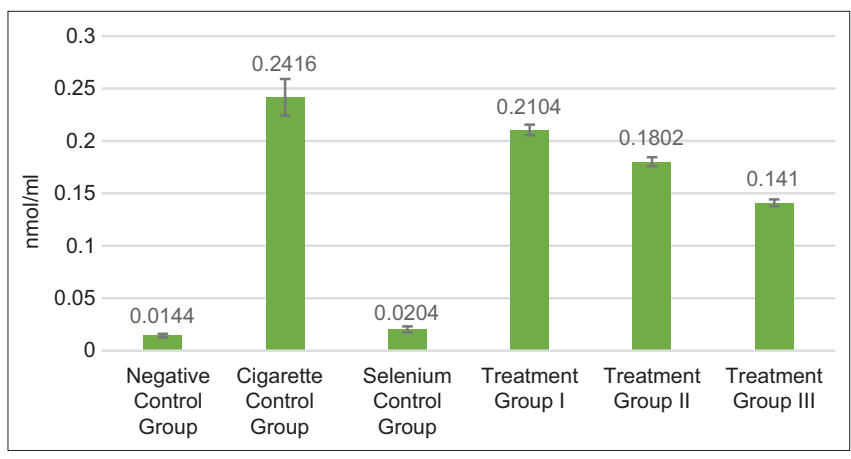

Fig. 3: The mean value for malondialdehyde in each group

MDA levels in blood as a result of exposure to e-cigarette smoke Research results were obtained by comparing levels of MDA in each group. Based on Fig. 3, the average value and difference of levels of MDA in each group can be known. The results showed that the negative control group had the lowest average value reaching $0.0144 \pm 0.0018$. Meanwhile, in the cigarette control group, it had the highest average value reaching $0.2416 \pm 0.0174$. In the treatment groups, there was an decrease in the average value of MDA sequentially.

To fulfill the parametric test requirements, the research results were subjected to normality test $(p>0.05)$ and homogeneity test $(p=0.000)$. Based on Table 3, Kruskal-Wallis test was conducted to know the difference of MDA levels in the groups $(\mathrm{p}=0.000)$.

\section{DISCUSSION}

E-cigarette smoke entering the airways will increase free radicals in the body. The enhancement of free radicals can trigger an increase of MDA as well as a decrease of the body's enzymatic antioxidants in the forms of SOD and GPx [25]. The free radicals are also actually needed in the body because they play an important role in the body's defense system [26]. However, the imbalance between amount of free radicals and antioxidants will cause the occurrence of cell damage $[27,28]$. Additional intake of selenium per oral is needed to stimulate antioxidant increase in the body $[29,30]$.

Administering Se in this research showed enhancement existence of SOD and GPx. The group with the highest increase of antioxidants was the Se control group. It was proven by higher enhancement of antioxidants compared to the negative control groups. Meanwhile, the cigarette control group had the lowest level of antioxidants. This was caused by an increase of the amount of free radicals entering the airways because of exposure to e-cigarette smoke. On the three treatment groups, there was antioxidant enhancement gradually. The first treatment group had a higher level of antioxidant due to the administration of Se done earlier than exposure to e-cigarette smoke. As a result, the body's enzymatic
Table 2: Analysis of variance test for glutathione peroxidase in each group

\begin{tabular}{llll}
\hline Groups & Definition & Mean \pm SD & p-value \\
\hline I & Negative control group & $236.2 \pm 7.3$ & 0.000 \\
II & Cigarette control group & $85.6 \pm 8.96$ & \\
III & Selenium control group & $330.6 \pm 13.22$ & \\
IV & Treatment Group I & $118.2 \pm 6.46$ & \\
V & Treatment Group II & $154.0 \pm 5.66$ & \\
VI & Treatment Group III & $256.4 \pm 6.69$ & \\
\hline
\end{tabular}

Table 3: Kruskal-Wallis test for malondialdehyde in each group

\begin{tabular}{llll}
\hline Groups & Definition & Mean \pm SD & p-value \\
\hline I & Negative control group & $0.0144 \pm 0.0018$ & 0.000 \\
II & Cigarette control group & $0.2416 \pm 0.0174$ & \\
III & Selenium control group & $0.0204 \pm 0.0028$ & \\
IV & Treatment Group I & $0.2104 \pm 0.0051$ & \\
V & Treatment Group II & $0.1802 \pm 0.0043$ & \\
VI & Treatment Group III & $0.1410 \pm 0.0032$ & \\
\hline
\end{tabular}

antioxidants were still able to reduce the free radicals entering through the airways. In the second treatment group, the administration of both exposures to e-cigarette and Se was done at the same time. Therefore, there was a decrease in the antioxidant level. The third treatment group indicated the lowest level of antioxidants of all other treatment groups. It happened because the free radicals had entered the airways earlier. Hence, the antioxidant enhancement did not show any significant increase.

Se is a supplement that plays an important role in human's health. The given Se intake is expected to be able to prevent the increase of antioxidants SOD and GPx as well as provide with potential hope as a therapy to prevent cell damage caused by exposure to e-cigarette [31].

\section{CONCLUSION}

Se is a micronutrient that can reduce free radicals due to exposure to e-cigarette smoke through enhancement of antioxidant enzymes such as SOD and GPx.

\section{AUTHORS' CONTRIBUTIONS}

All the authors have contributed equally in research, review, and finalization of the contents of the journal.

\section{CONFLICTS OF INTEREST}

Declare None.

\section{REFERENCES}

1. Canistro D, Vivarelli F, Cirillo S, Marquillas CB, Buschini A, Lazzaretti M, et al. E-cigarettes induce toxicological effects that can raise the cancer risk. Sci Rep 2017;7:2028.

2. Grana R, Benowitz N, Glantz SA. E-cigarettes: A scientific review. Circulation 2014;129:1972-86.

3. Vardavas CI, Anagnostopoulos N, Kougias M, Evangelopoulou V, Connolly GN, Behrakis PK, et al. Short-term pulmonary effects of using an electronic cigarette: Impact on respiratory flow resistance, impedance, and exhaled nitric oxide. Chest 2012;141:1400-6.

4. Polosa R, Caponnetto P, Morjaria JB, Papale G, Campagna D, Russo C, et al. Effect of an electronic nicotine delivery device (e-cigarette) on smoking reduction and cessation: A prospective 6-month pilot study. BMC Public Health 2011;11:786.

5. Suryadinata RV, Wirjatmadi B, Adriani M. Effectiveness Decrease Combined with Supplements Malondialdehyde Antioxidant Superoxide Dismutase Gliadin Melon with Due to Exposure to Cigarette. Glob Med Heal Commun 2017;5:79-83.

6. Suryadinata RV. Effect of free radicals on inflammatory process in chronic obstructive pulmonary disease (COPD). Amerta Nutr 
2018;2:317-24.

7. Raghavendra U, Rao A, D'souza J, Pai VR, Nair S, Kumar V, et al. Comparative estimation of salivary total antioxidant capacity in periodontal health and chronic periodontitis a pilot study. Asian J Pharm Clin Res 2018;11:523.

8. Ayala A, Muñoz MF, Argüelles S. Lipid peroxidation: Production, metabolism, and signaling mechanisms of malondialdehyde and 4-hydroxy-2-nonenal. Oxid Med Cell Longev 2014;2014:360438.

9. Mapunda PE, Mligo C, Lyaruu HV. Evaluation of free radical scavenging ability and antiradical activities of Ximenia caffra fruit extracts at different ripening stages. Int J Pharm Pharm Sci 2019;11:55.

10. Pratiwi SR, Lorensia A, Suryadinata RV. Asupan Vitamin C dan E dengan SQ-FFQ terhadap fungsi paru perokok dan non-perokok. Media Kesehatan Masyarakat Indones 2018;14:101.

11. Subba A, Mandal P. Standardization of a traditional polyherbal formulation with pharmacognostic study; its phytochemical content, antioxidant, and antidiabetic activity. Asian J Pharm Clin Res 2019;12:5.

12. Rahal A, Kumar A, Singh V, Yadav B, Tiwari R, Chakraborty S, et al. Oxidative stress, prooxidants, and antioxidants: The interplay. Biomed Res Int 2014;2014:761264

13. Pratima H. Antioxidant and antibacterial activity of alkaloid extract of Cucumis trigonus Roxb. Int J Pharm Pharm Sci 2019;11:44-8.

14. Liguori I, Russo G, Curcio F, Bulli G, Aran L, Della-Morte D, et al. Oxidative stress, aging, and diseases. Clin Interv Aging 2018;13:757-72.

15. Suryadinata RV, Wirjatmadi B, Adriani M. Effects of Changes in Goblet Cell Hyperplasia for 28 Days of Cigarette Smoke Exposure through the administration of Antioxidant Superoxide Dismutase. Indones J Public Health 2017:11:60

16. Lubos E, Loscalzo J, Handy DE. Glutathione peroxidase-1 in health and disease: From molecular mechanisms to therapeutic opportunities. Antioxid Redox Signal 2011;15:1957-97.

17. Phaniendra A, Jestadi DB, Periyasamy L. Free radicals: Properties, sources, targets, and their implication in various diseases. Indian J Clin Biochem 2015;30:11-26.

18. Kim Y, Kim DC, Cho ES, Ko SO, Kwon WY, Suh GJ, et al. Antioxidant and anti-inflammatory effects of selenium in oral buccal mucosa and small intestinal mucosa during intestinal ischemia-reperfusion injury. J Inflamm (Lond) 2014;11:36.

19. Socha K, Kochanowicz J, Karpińska E, Soroczyńska J, Jakoniuk M,
Mariak Z, et al. Dietary habits and selenium, glutathione peroxidase and total antioxidant status in the serum of patients with relapsingremitting multiple sclerosis. Nutr J 2014;13:62.

20. Bermingham EN, Hesketh JE, Sinclair BR, Koolaard JP, Roy NC. Selenium-enriched foods are more effective at increasing glutathione peroxidase (GPx) activity compared with selenomethionine: A metaanalysis. Nutrients 2014;6:4002-31.

21. Mehdi Y, Hornick JL, Istasse L, Dufrasne I. Selenium in the environment, metabolism and involvement in body functions. Molecules 2013;18:3292-311.

22. Cai X, Wang C, Yu W, Fan W, Wang S, Shen N, et al. Selenium exposure and cancer risk: An updated meta-analysis and meta-regression. Sci Rep 2016;6:19213.

23. Kim KS, Suh GJ, Kwon WY, Kwak YH, Lee K, Lee HJ, et al. Antioxidant effects of selenium on lung injury in paraquat intoxicated rats. Clin Toxicol (Phila) 2012;50:749-53

24. Younus $\mathrm{H}$. Therapeutic potentials of superoxide dismutase. Int J Health Sci (Qassim) 2018;12:88-93.

25. Suryadinata RV, Wirjatmadi B, Adriani M, Sumarmi S. The effects of exposure duration to electronic cigarette smoke on differences in superoxide dismutase and malondialdehyde in blood of wistar rats. Int J Curr Pharm Res 2019;11:13-6.

26. Chidambararajan P, Keerthana V, Priyadharshini K, Sakthivel B. In vitro antioxidant and anticancer activity of ulva lactucal 1 . Using MOLT-3 cell line. Asian J Pharm Clin Res 2019;12:3-6.

27. Simioni C, Zauli G, Martelli AM, Vitale M, Sacchetti G, Gonelli A, et al. Oxidative stress: Role of physical exercise and antioxidant nutraceuticals in adulthood and aging. Oncotarget 2018;9:17181-98.

28. Jing SL, Yen KP, Dash GK. In vitro antioxidant and photoprotective activities of Carica papaya fruits. Asian J Pharm Clin Res 2019;12:2-4.

29. Lobo V, Patil A, Phatak A, Chandra N. Free radicals, antioxidants and functional foods: Impact on human health. Pharmacogn Rev 2010;4:118-26.

30. Pizzino G, Irrera N, Cucinotta M, Pallio G, Mannino F, Arcoraci V, et al. Oxidative stress: Harms and benefits for human health. Oxid Med Cell Longev 2017;2017:8416763.

31. Wang N, Tan HY, Li S, Xu Y, Guo W, Feng Y, et al. Supplementation of micronutrient selenium in metabolic diseases: Its role as an antioxidant. Oxid Med Cell Longev 2017;2017:7478523. 